\title{
An additional measure of availability derived from the Oxford English Dictionary
}

\author{
THOMAS R. KEENAN \\ Ontario Institute for Studies in Education, Toronto, Ontario, Canada \\ and \\ JOHN G. BENJAFIELD \\ Brock University, St. Catharines, Ontario, Canada
}

\begin{abstract}
In order to develop an additional measure of availability for the nouns from Paivio, Yuille, and Madigan's (1968) list, we used a CD-ROM version of the Oxford English Dictionary (OED) to obtain the number of times a word was used to define other words. This variable was added to Rubin and Friendly's (1986) set of measures for these words. In multiple regression analyses, our measure proved to be a useful predictor of free recall. These results suggest that the OED may be useful for providing additional psycholinguistic measures.
\end{abstract}

Rubin and Friendly (1986) have compiled an extensive survey of the factors that determine which words get recalled in free-recall tasks. Using Paivio, Yuille, and Madigan's (1968) list of 925 nouns, Rubin and Friendly collected normative data on a wide-ranging set of variables, including measures of orthography, pronounceability, imagery, concreteness, meaningfulness, availability, familiarity, frequency of occurrence, goodness, and emotionality. These measures were then correlated with recall data from a series of experiments that were designed to explore the determinants of the likelihood that a word will be recalled.

Rubin and Friendly's analyses indicated that imagery, emotionality, and availability were the best predictors of the nouns that would be recalled by subjects. The first two results-that imagery and emotionality can have strong effects on recall-are well established in the literature (e.g., Rubin, 1980). Rubin and Friendly (1986, p. 85) note that the finding that availability is an important predictor of which words get recalled is somewhat surprising, given that this variable has not been as widely researched as some of the others (see Rubin, 1980, 1983).

Availability can be defined as the ease with which a word comes to mind as a label for experience (Asch \& Ebenholtz, 1962; Rubin, 1983), and may be thought of as the converse of measures of meaningfulness (Rubin \& Friendly, 1986). Since meaningfulness is usually defined

Correspondence concerning this article should be sent to J. Benjafield, Department of Psychology, Brock University, St. Catharines, Ontario, Canada L2S 3A1. We are grateful to David Rubin for providing us with the Rubin and Friendly (1986) data. Our availability data may be obtained from the second author (jbenjafi@spartan.ac.brocku.ca) either on disk or by e-mail. as the number of associates that are given to a word, defining availability as the converse of meaningfulness means that it is measured by the number of associates leading to a given word. Our aim in the present study was to develop an additional measure of availability that would give an accurate representation of the ease with which a word comes to mind, and be easily obtainable as well. To this end, we employed a CD-ROM version of the $O x$ ford English Dictionary (OED; 1987).

\section{METHOD}

Our measure of availability was obtained by searching the OED CDROM using a function that yields the number of times a word is used in the definition of other words. This is an index of availability, because it measures the number of connections a word has to other words within the network of relationships embodied in the written language.

Our availability measure was added to Rubin and Friendly's (1986) set of variables, which included length in letters ( $L$ ); first-order approximation to English (FOA); second-order approximation to English (SOA); pronounceability $(\mathrm{Pr})$; imagery $(\mathrm{I})$; concreteness $(\mathrm{C})$; meaningfulness (M); Kiss availability (KA); availability (A); familiarity (F); KuCeraFrancis frequency (KFF); Thorndike-Lorge frequency (TLF); goodness (G); emotionality (E); emotional goodness (EG); free recall (FR); free-recall Trial 1 (FR1); free-recall Trial 2 (FR2); free-recall Trial 3 (FR3); free-recall CBTC (FRC, from Christian, Bickley, Tarka, \& Clayton, 1978); and free recall averaged (FRA). Details of these measures can be found in Rubin and Friendly's paper.

The variables with which we will be particularly concerned are availability, Kiss availability, Kucera-Francis frequency, Thorndike-Lorge frequency, and free recall averaged; a brief description of each of these is in order. Availability is derived from Palermo and Jenkins's (1964) word-association norms, and it varies with the frequency with which a word is given as an associate. Kiss availability (Kiss, 1975) is derived from British data on the number of times a word is given as an associate to some other word. KuCera-Francis frequency and ThorndikeLorge frequency are the familiar word frequency norms of Kucera and Francis (1967) and Thorndike and Lorge (1944). Free recall averaged is derived from the first three trials of a multiple-trial free-recall experiment combined with the free-recall data from Christian et al. (1978). 
Table 1

Correlations Between Oxford English Dictionary Availability (OA) and Rubin and Friendly's (1986) Variables

\begin{tabular}{|c|c|c|c|}
\hline Variable & OA & Variable & OA \\
\hline Length in letters & $-.31 \dagger$ & Thorndike-Lorge frequency & $.48+$ \\
\hline First-order approximation & $.32 \dagger$ & Goodness & $.22 \dagger$ \\
\hline Second-order approximation & $.35 \dagger$ & Emotionality & $.10 \dagger$ \\
\hline Pronounceability & $-.35 \dagger$ & Emotional goodness & $.10 \dagger$ \\
\hline Imagery & $.08 *$ & Free recall & .04 \\
\hline Concreteness & -.01 & Free recall 1 & .04 \\
\hline Meaningfulness & $.19 \dagger$ & Free recall 2 & .04 \\
\hline Kiss availability & $.38 \dagger$ & Free recall 3 & .04 \\
\hline Availability & $.42 \dagger$ & Free recall CBTC & $.21 \dagger$ \\
\hline Familiarity & $.41 \dagger$ & Free recall averaged & $.21 \dagger$ \\
\hline Kucera-Francis frequency & $.55 \dagger$ & & \\
\hline
\end{tabular}

\section{RESULTS}

Correlations between the OED availability measure (OA) and Rubin and Friendly's (1986) variables are given in Table 1. When our data were added to Rubin and Friendly's data and factor analyzed using a principalfactor orthogonal varimax procedure, the result was quite similar to that obtained by Rubin and Friendly. Our availability measure loaded on the same factor as did their availability measures; factor loadings are available from the second author upon request.

Multiple regression analyses were done to determine whether OA is a useful predictor of free recall averaged (FRA). These analyses were performed on a sample of 899 words-fewer than the 925 in Paivio et al.'s (1968) original sample-due to the fact that only the words for which all data were available were included in our analyses, and that some words (e.g., speakeasy, racketeer) were not listed in this version of the OED. The results of the multiple regression analyses are given in Table 2 . The first analysis mimics that done by Rubin and Friendly (1986, p. 85) by including all predictor variables except those that correlate .85 with other predictor variables. The variables are listed in Table 2 in the order in which they were entered in a stepwise regression; the restriction was that a variable must have a significant $(p<.05)$ beta weight to be entered. Our results are similar to Rubin and Friendly's results (1986, Table 1) in that imagery (I and C), availability (A and $\mathrm{OA}$ ), and emotionality (EG and E) are three important classes of variables. However, in our analysis, $O A$ enters the analysis in fifth place, whereas
Kiss availability, which entered Rubin and Friendly's analysis in sixth position, does not enter our analysis at all.

In a second stepwise multiple regression, again with FRA as the dependent variable, we explored the relative importance of the three measures of availability. All three measures are significant predictors, but, as shown in Table 2 , A enters first, followed by OA, and finally by KA. In a third analysis we compared the predictive efficacy of OA with the two measures of frequency. As shown in Table 2, OA is the best of these three predictors of FRA. As Rubin and Friendly (1986) found, the beta weight for Thorndike-Lorge frequency is negative, even though its simple correlation with FRA is positive, suggesting that this variable acts as a suppressor variable. That is, Thorndike-Lorge frequency removes part of the variance of Kučera-Francis frequency in such a way as to improve the overall multiple correlation (Cohen \& Cohen, 1983, pp. 94-96).

\section{DISCUSSION}

Our analyses support the notion that $\mathrm{OA}$ is a useful additional measure of availability. It makes a significant contribution to the prediction of free recall (1) when combined with all other variables, (2) when combined with other measures of availability, and (3) when combined with measures of frequency. We suggest that our data show that the OED is potentially a very useful research tool, allowing researchers to develop a variety of measures of their word samples, such as date of entry (e.g., Benjafield \& Muckenheim, 1989a) and availability. Such measures can easily be obtained by researchers for virtually any word sample.

On a more theoretical level, our use of the OED follows from a general theoretical orientation devoted to uncovering relationships between historical and psychological variables (e.g., Benjafield, 1987a; Benjafield \& Muckenheim, 1989a, 1989b). The OED is organized historically; each

Table 2

Beta Weights From Three Stepwise Multiple Regressions With Free Recall Averaged (FRA) as the Dependent Variable

\begin{tabular}{|c|c|c|c|c|c|c|c|c|c|c|c|}
\hline \multirow{2}{*}{$\begin{array}{c}\text { Dependent } \\
\text { Variable }\end{array}$} & \multicolumn{10}{|c|}{ Independent Variables } & \multirow[b]{2}{*}{$R$} \\
\hline & 1 & 2 & 3 & 4 & 5 & 6 & 7 & 8 & 9 & 10 & \\
\hline FRA & $.30 \mathrm{I}$ & $.13 \mathrm{~A}$ & $.12 \mathrm{EG}$ & $-.13 \mathrm{~F}$ & $.130 \mathrm{~A}$ & $-.16 \mathrm{~L}$ & $.25 \mathrm{C}$ & $.07 \mathrm{G}$ & $.10 \mathrm{E}$ & $.10 \mathrm{Pr}$ & .59 \\
\hline FRA & $.22 \mathrm{~A}$ & $.09 \mathrm{OA}$ & $.07 \mathrm{KA}$ & & & & & & & & .31 \\
\hline FRA & $.220 \mathrm{~A}$ & $.27 \mathrm{KFF}$ & $-.27 \mathrm{TLF}$ & & & & & & & & .27 \\
\hline
\end{tabular}

Note-I = imagery; $A$ = availability; $E G=$ emotional goodness; $F=$ familiarity; $O A=0$ OED availability; $\mathrm{L}=$ length in letters; $\mathrm{C}=$ concreteness; $\mathrm{G}=$ goodness; $\mathrm{E}=$ emotionality; $\mathrm{Pr}=$ pronounceability; $\mathrm{KA}=$ Kiss availability; KFF $=$ Kucera-Francis frequency; TLF $=$ Thorndike-Lorge frequency. 
entry traces the historical development of a word. Our availability measure is at least partly determined by the history of the words we have sampled. For example, words that have a long history will tend to be used more frequently than words that are more recent (Benjafield, 1987b). The fact that our availability measure can be used to predict free recall suggests that memory and other cognitive processes may fruitfully be seen as being partly the product of an historical process. Classical psychologists, such as Piaget (1971) and Vygotsky (1934/1986), pointed out the relevance of examining cognitive processes as being at least partly the outcome of a process of historical development, and we hope that our study contributes in a small way toward encouraging cognitive psychologists to include historically relevant variables in their investigations.

\section{REFERENCES}

Asch, S. E., \& Ebenholtz, S. M. (1962). The principle of associative symmetry. Proceedings of the American Philosophical Society, 106, 135-163.

BENJAFIELD, J. (1987a). An historical, social analysis of imagery and concreteness. British Journal of Social Psychology, 26, 155-164.

BENJAFIELD, J. (1987b). An historicodevelopmental analysis of the frequency with which construct poles are used. Canadian Joumal of Behavioural Science, 19, 332-341.

Benjafield, J., \& MuCKenheim, R. (1989a). Dates of entry and measures of imagery, concreteness, goodness, and familiarity for 1,046 words sampled from the Oxford English Dictionary. Behavior Research Methods, Instruments, \& Computers, 21, 31-52.

Benjafield, J., \& Muckenheim, R. (1989b). A further historicodevelopmental study of the interpersonal circumplex. Canadian Joumal of Behavioural Science, 21, 83-93.

Christian, J., Bickley, W., Tarka, M., \& Clayton, K. (1978). Measures of free recall of 900 English nouns: Correlations with imagery, concreteness, meaningfulness, and frequency. Memory \& Cognition, 6, 379-390.
Cohen, J., \& Cohen, P. (1983). Applied multiple regression/correlation analysis for the behavioral sciences (2nd ed.). Hillsdale, NJ: Erlbaum.

KIss, G. R. (1975). An associative thesaurus of English: Structural analysis of a large relevance network. In A. Kennedy \& A. Wilkes (Eds.), Studies in long-term memory (pp. 103-121). London: Wiley.

KuČERA, H., Francis, W. N. (1967). Computational analysis of present-day American English. Providence, RI: Brown University Press.

Oxford English Dictionary [CD-ROM ed.] (1987). Ft. Washington, PA: Tri-Star Publishing.

Paivio, A., Yuille, J. C., \& Madigan, S. A. (1968). Concreteness, imagery, and meaningfulness values for 925 nouns. Journal of Experimental Psychology Monographs, 76(1, Pt. 2).

Palermo, D. S., \& Jenkins, J. J. (1964). Word association norms. Minneapolis: University of Minnesota Press.

Piage , J. (1971). Structuralism. New York: Harper.

RubiN, D. C. (1980). 51 properties of 125 words: A unit analysis of verbal behavior. Journal of Verbal Learning \& Verbal Behavior, 19, 736-755.

RuBIN, D. C. (1983). Associative asymmetry, availability, and retrieval. Memory \& Cognition, 11, 83-92.

RubIN, D. C., \& FRIENDLY, M. (1986). Predicting which words get recalled: Measures of free recall, availability, goodness, emotionality, and pronounceability for 925 nouns. Memory \& Cognition, 14, 79-94.

THORNDIKE, E. L., \& LORGE, I. (1944). The teacher's word book of 30,000 words. New York: Teachers College Press, Columbia University.

VyGoTSKy, L. S. (1986). Thought and language (A. Kozulin, Trans.). Cambridge, MA: MIT Press. (Original work published 1934)

(Manuscript received September 10, 1993; revision accepted for publication February 16, 1994.) 